\title{
Mitochondrial DNA Polymorphism in Jindo Dogs
}

\author{
Fuminori UMENISHI, Bang Keun $\mathrm{HAN}^{1)}$, and Shigenori IKEMOTO \\ Department of Legal Medicine and Human Genetics, Jichi Medical School, Minamikawachi-machi, Kawachi-gun, Tochigi-ken 329-04, \\ Japan and ${ }^{1)}$ College of Veterinary Medicine, Chonnam National University, \#300, Yongbong-Dong, Kwangju 500-757, Republic of \\ Korea
}

(Received 10 September 1992/Accepted 14 January 1993)

ABSTRACT. Mitochondrial DNA (mtDNA) polymorphism was studied in 21 Jindo dogs inhabiting Jin Island off the Korean peninsula. The polymorphism was analyzed with 10 restriction endonucleases that recognize six base pairs. The sizes of the mtDNA fragments produced by digestion using each endonucleases were separated by agarose gel electrophoresis, and the polymorphisms were detected with Japanese mongrel dog mtDNA as a probe. The mtDNA polymorphism in Jindo dogs was observed with four restriction endonucleases, Apa I, EcoR V, Hinc II, and Sty I. However, no polymorphism was detected with BamH I, Bgl II, EcoR I, Hind III, Pst $\mathrm{I}$, or $\mathrm{Xba} \mathrm{I}$. The observed restriction endonuclease morphs were classified into 4 types of distinct cleavage patterns. The average number of nucleotide substitutions per nucleotide site in Jindodogs was estimated to be 0.0086 . By UPG phylogenetic analysis, the $4 \mathrm{mtDNA}$ types showed only one cluster. This suggests that Jindo dogs have not diverged from the other cluster up to the present and the species is considerably pure.-KEY wORDS: Japanese mongrel dog, Jindo dog, mitochondrial DNA (mtDNA), polymorphism, restriction endonuclease.

J. Vet. Med. Sci. 55(2): 313-317, 1993

Mammalian mitochondrial DNA (mtDNA), which is a closed circular molecule of approximately $16.5 \mathrm{~kb}$ pairs, is maternally inherited, and the evolutionary rate of nucleotide substitution is very rapid $[1,2,4]$. MtDNA polymorphisms based on the analysis of restriction endonuclease have therefore become a very useful tool to examine the genetic relationships between various species.

Many researchers have been investigating the polymorphisms of mtDNA in several mammalian species [7, 10-13]. However, there have been few data concerning mtDNA polymorphisms in dogs. Recently, Tsuchida and Ikemoto [9] have reported mtDNA polymorphisms in Japanese mongrel dogs. The polymorphism was observed in the cleavage patterns of Apa I, EcoR I, EcoR V, Hinc II, and Sty I; three morphs were found in $A p a \mathrm{I}$ and $E c o \mathrm{R}$ I, and two morphs were in EcoR V, Hinc II and Sty I. The morphs observed were classified into 7 types and the value for nucleotide diversity was estimated to be 0.0055 . A phylogenetic tree constructed from genetic distances among 7 types showed at least two clusters of mtDNA.

The Jindo dog (Korean native dog) inhabits Jin Island off the Korean peninsula. This breed has been designated as a special natural monument by the Korean government and exists only this island. We are interested in the reason why the Jindo dog is very similar to the Japanese native dog in appearance. To investigate this, we have conducted a phylogenetic investigation of the native dogs in Korea which enables us to speculate as to the route by which dogs came over to the islands of Japan. In the present study we investigated the mtDNA polymorphisms in 21 Jindo dogs with 10 restriction endonucleases that recognize six base pairs. We also discussed the genetic relation between the Jindo dog and the Japanese mongrel dog.

\section{MATERIALS AND METHODS}

Amimals: The DNA samples were prepared from the peripheral bloods of unrelated 21 Jindo dogs and were used for the analysis of mtDNA polymorphism.

Restriction endonuclease digestion, agarose gel electrophoresis, and Southern blotting: The following endonucleases were used: $A p a \mathrm{I}, B a m \mathrm{H}$ I, $B g l \mathrm{II}, E c o \mathrm{R}$ I, EcoR V, Hinc II, Hind III, Pst I, Sty I, and Xba I (Takara Shuzo Co., Ltd., GIBCO BRL, and Nippon Gene Co., Ltd.). Five $\mu \mathrm{g}$ of each DNA obtained from the blood of 21 Jindo dogs was digested in a fivefold excess of enzyme at $37^{\circ} \mathrm{C}$ for $6 \mathrm{hr}$. The restricted DNA was run in $0.8 \%$ agarose gel in TAE buffer ( $40 \mathrm{mM}$ Tris-acetate containing $1 \mathrm{mM}$ EDTA) at a constant voltage of $20 \mathrm{~V}$, except for Hinc II and Sty I, which were in $1.2 \%$ agarose gel. The gels were soaked in $0.15 \mathrm{M} \mathrm{HCl}$ for $15 \mathrm{~min}$, denatured in $0.5 \mathrm{~N} \mathrm{NaOH}$ containing $1.5 \mathrm{M} \mathrm{NaCl}$ for $45 \mathrm{~min}$ and neutralized in $0.5 \mathrm{M}$ Tris- $\mathrm{HCl}(\mathrm{pH} 7.2)$ containing $1.5 \mathrm{M}$ $\mathrm{NaCl}$ and $1 \mathrm{mM}$ EDTA for two 15 min periods. The gels were then blotted overnight onto nylon membranes (Hybond-N, Amersham) with $20 \times$ SSPE buffer $(0.2 \mathrm{M}$ $\mathrm{NaH}_{2} \mathrm{PO}_{4}(\mathrm{pH} 7.7)$ containing $3.6 \mathrm{M} \mathrm{NaCl}$ and $0.02 \mathrm{M}$ EDTA). After blotting, the filters were briefly washed in $2 \times$ SSPE and fixed at UV for $5 \mathrm{~min}$.

Labeling of the probe and hybridization: In this study, mtDNA prepared from the kidneys of Japanese mongrel dogs was used as a probe. Mongrel $\operatorname{dog}$ mtDNA was prepared by the method of Lansman et al. [5]. The mtDNA was ${ }^{32}$ P-labeled by the multiprime method using multiprime DNA labeling systems (Amersham). The blotted filters were prehybridized for $1 \mathrm{hr}$ at $65^{\circ} \mathrm{C}$, and hybridized for $18 \mathrm{hr}$ at $65^{\circ} \mathrm{C}$ after the addition of the probe. The filters were washed in $2 \times \mathrm{SSPE}, 1 \times \mathrm{SSPE}$ and $0.1 \times$ SSPE containing $0.1 \%$ SDS at room temperature in 
turn, and exposed at $-70^{\circ} \mathrm{C}$ to Fuji AIF New RX films for 1 to 3 days.

Nucleotide diversity in mtDNA of the Jindo dog: The average amount of nucleotide change in the mtDNA of the Jindo dog was estimated by the method of cleavage site comparisons [6]. First, we estimated the proportions (S) of shared restriction sites in any two restriction types by using the equation of $\mathrm{Nei} \& \mathrm{Li}: \mathrm{S}=2 \mathrm{Nxy} /(\mathrm{Nx}+\mathrm{Ny})$, where $\mathrm{Nx}$ and $\mathrm{Ny}$ are the numbers of restriction sites in type $\mathrm{x}$ and $\mathrm{y}$, respectively, and $\mathrm{Nxy}$ is the number of restriction sites shared by types $x$ and $y$. The number (d) of nucleotide substitutions per nucleotide site was estimated by using the equation of Nei \& $\mathrm{Li}$ : $d=-(3 /$ $2) \ln \left(\left(4 S^{1 / 2 r}-1\right) / 3\right)$, where $r$ is the number of nucleotides of the restriction sequence for restriction endonucleases used. In this study $r$ is equal to 6 .

RESULTS

Cleavage patterns with restriction endonucleases in Jindo $\operatorname{dog} m t D N A$ : Patterns of cleavage of mtDNA by restriction endonucleases were investigated for 21 Jindo dogs. Ten kinds of restriction endonucleases which recognize six base pairs were used in this study. MtDNA polymorphisms in Jindo dogs were observed in the restriction patterns with ApaI, EcoRV, HincII, and StyI, but no difference was observed in the patterns generated by the other six endonucleases. Figures 1, 2, 3, and 4 show the cleavage patterns for Jindo dogs mtDNA obtained with four restriction endonucleases, and Table 1 shows the numbers of Jindo dog mtDNA cleavage sites for 10 restriction endonucleases and the length of the fragments. The number and frequency of mtDNA morphs in Jindo dogs are also summarized in Table 2.

ApaI: Three different cleavage patterns were observed with ApaI (Fig. 1 and Table 1). Morph B has two fragments of approximately 11.6 and $4.9 \mathrm{~kb}$. Morph $\mathrm{C}$ is generated by the loss of the $11.6 \mathrm{~kb}$ band in morph $\mathrm{B}$ and the appearance of three smaller fragments: $6.7,3.7$, and $1.2 \mathrm{~kb}$. The dominant pattern, morph $\mathrm{A}$, had two fragments $(6.7$ and $4.9 \mathrm{~kb})$. They overlapped the $6.7 \mathrm{~kb}$ and $4.9 \mathrm{~kb}$ fragments of morph $\mathrm{C}$. Therefore, it is considered that morph A has three fragments: 6.7, 4.9 and another $4.9 \mathrm{~kb}$. To confirm this expectation, double digestion with ApaI and PstI was performed for morph A and generated four bands: $6.7,4.9,4.7$, and $0.2 \mathrm{~kb}$ (data not shown), indicating that morph $\mathrm{A}$ has three cleavage sites. That is, another $4.9 \mathrm{~kb}$ fragment in morph $\mathrm{A}$ is generated by fusion of 3.7 and $1.2 \mathrm{~kb}$ fragments of morph C.

EcoR V: Two different morphs were found in this study (Fig. 2 and Table 1). Morph A has three fragments (13.0, 2.1 , and $1.4 \mathrm{~kb}$ ). Morph B had four fragments-10.3, 2.7, 2.1 , and $1.4 \mathrm{~kb}-$ by generating one more cleavage site in the $13.0 \mathrm{~kb}$ fragment.

Hinc II: Two different morphs were observed (Fig. 3

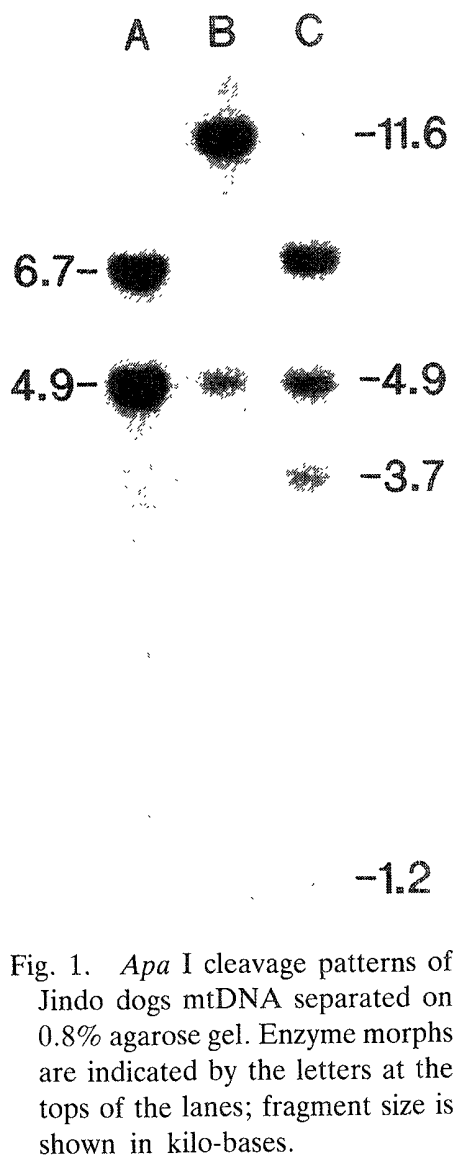

A B

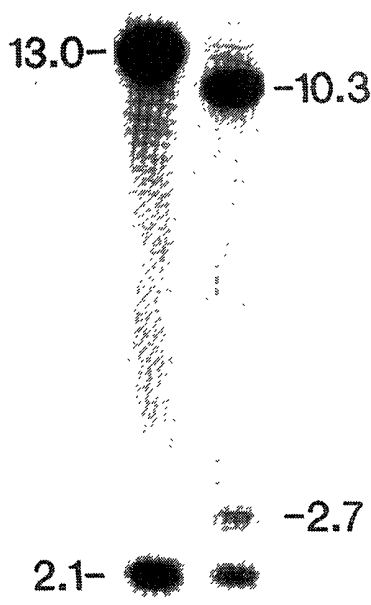

$1.4-$

Fig. 2. EcoR V cleavage patterns of Jindo dogs mtDNA separated on $0.8 \%$ agarose gel.
A B

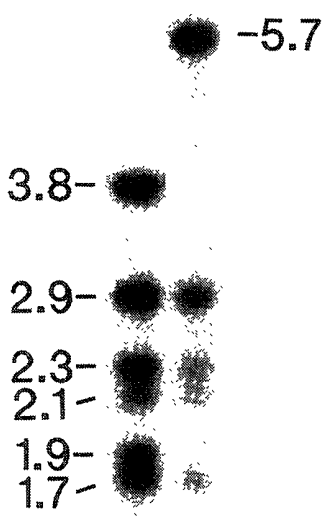

$1.0-$

$0.8-$

Fig. 3. Hinc II cleavage patterns of Jindo dogs mtDNA separated on $1.2 \%$ agarose gel. 
and Table 1). Morph A has eight fragments: 3.8, 2.9, 2.3, $2.1,1.9,1.7,1.0$, and $0.8 \mathrm{~kb}$. On the other hand, a $5.7 \mathrm{~kb}$ fragment in morph $\mathrm{B}$ is generated by fusion of 3.8 and 1.9 $\mathrm{kb}$ fragments of morph $\mathrm{A}$. Consequently, morph $\mathrm{B}$ has seven fragments caused by the loss of a Hinc II site.

Table 1. Numbers of Jindo dog mtDNA cleavage sites for 10 restriction endonucleases and the length of fragments

\begin{tabular}{|c|c|c|c|c|c|c|}
\hline \multirow{2}{*}{$\begin{array}{l}\text { Enzymes } \\
\text { Apa I }\end{array}$} & \multirow{2}{*}{$\frac{\text { Morphs }}{\mathrm{A}}$} & \multirow{2}{*}{$\begin{array}{c}\begin{array}{c}\text { Number of } \\
\text { cleavage sites }\end{array} \\
3\end{array}$} & \multicolumn{4}{|c|}{$\begin{array}{l}\text { Length of fragments } \\
\qquad(\mathrm{kb})\end{array}$} \\
\hline & & & 6.7 & 4.9 & 4.9 & \\
\hline & B & 2 & 11.6 & 4.9 & & \\
\hline & C & 4 & 6.7 & 4.9 & 3.7 & 1.2 \\
\hline \multirow[t]{2}{*}{$E c o \mathrm{R} \mathrm{V}$} & A & 3 & 13.0 & 2.1 & 1.4 & \\
\hline & B & 4 & 10.3 & 2.7 & 2.1 & 1.4 \\
\hline \multirow[t]{4}{*}{ Hinc II } & A & 8 & 3.8 & 2.9 & 2.3 & 2.1 \\
\hline & & & 1.9 & 1.7 & 1.0 & 0.8 \\
\hline & B & 7 & 5.7 & 2.9 & 2.3 & 2.1 \\
\hline & & & 1.7 & 1.0 & 0.8 & \\
\hline \multirow{4}{*}{ Sty I } & A & 9 & 4.2 & 2.6 & 2.35 & 2.15 \\
\hline & & & $\begin{array}{l}1.95 \\
0.1\end{array}$ & 1.65 & 1.0 & 0.5 \\
\hline & B & 8 & 4.2 & 2.6 & 2.45 & 2.15 \\
\hline & & & 1.95 & 1.65 & 1.0 & 0.5 \\
\hline BamH I & A & 3 & 11.5 & 3.7 & 1.3 & \\
\hline$B g l$ II & A & 3 & 9.1 & 4.0 & 3.4 & \\
\hline EcoR I & A & 3 & 8.4 & 7.3 & 0.8 & \\
\hline Hind III & A & 2 & 14.4 & 1.9 & & \\
\hline Pst I & A & 1 & 16.5 & & & \\
\hline$X b a \mathrm{I}$ & A & 2 & 13.5 & 3.0 & & \\
\hline
\end{tabular}

\section{A B}
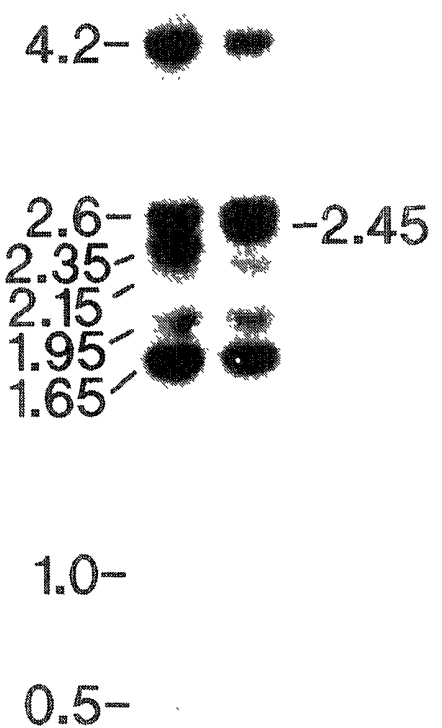

Fig. 4. Sty I cleavage patterns of Jindo dogs mtDNA separated on $1.2 \%$ agarose gel.
Sty I: Two different morphs were found in the present study (Fig. 4 and Table 1). Morph A showed nine fragments of $4.2,2.6,2.35,2.15,1.95,1.65,1.0,0.5$, and $0.1 \mathrm{~kb}$ (no $0.1 \mathrm{~kb}$ band was detected under these conditions). In morph B a $2.45 \mathrm{~kb}$ fragment could be visualized on account of the fusion of the contiguous fragments $(2.35$ and $0.1 \mathrm{~kb})$ caused by the loss of a Sty I site.

$B a m H$ I, Bgl II, EcoR I, Hind III, Pst I, and Xba I: These six endonucleases had no polymorphism. These results are shown in Table 1.

\begin{tabular}{|c|c|c|c|}
\hline \multirow{2}{*}{ Enzymes } & \multirow{2}{*}{ Morphs } & \multicolumn{2}{|r|}{ Jindo dog } \\
\hline & & No. & Frequency $(\%)$ \\
\hline \multirow[t]{3}{*}{ Apa I } & A & 15 & 71.5 \\
\hline & $B$ & 4 & 19.0 \\
\hline & $\mathrm{C}$ & 2 & 9.5 \\
\hline \multirow[t]{2}{*}{$E c o R$ V } & A & 18 & 85.7 \\
\hline & $\mathrm{B}$ & 3 & 14.3 \\
\hline \multirow[t]{2}{*}{ Hinc II } & A & 18 & 85.7 \\
\hline & $\mathrm{B}$ & 3 & 14.3 \\
\hline \multirow[t]{2}{*}{ Sty 1} & A & 18 & 85.7 \\
\hline & $\mathrm{B}$ & 3 & 14.3 \\
\hline $\operatorname{BamH~I}$ & $\mathrm{A}$ & 21 & 100.0 \\
\hline$B g l$ П & A & 21 & 100.0 \\
\hline EcoR I & A & 21 & 100.0 \\
\hline Hind III & $\mathrm{A}$ & 21 & 100.0 \\
\hline Pst I & A & 21 & 100.0 \\
\hline$X b a I$ & $\mathrm{~A}$ & 21 & 100.0 \\
\hline
\end{tabular}

Table 3. MtDNA types based on the morphs observed in 21 Jindo dogs using four restriction endonucleases

\begin{tabular}{|c|c|c|c|c|c|c|}
\hline \multirow{2}{*}{ Types $^{\text {a) }}$} & \multicolumn{4}{|c|}{ Enzyme morphs } & \multicolumn{2}{|c|}{ Jindo dog } \\
\hline & Apa I & $E c o \mathrm{R}$ & $V$ Hinc II & Sty I & No. & $\%$ \\
\hline 1 & A & A & A & A & 15 & 71.4 \\
\hline 2 & B & A & A & A & 1 & 4.8 \\
\hline 3 & B & B & B & B & 3 & 14.3 \\
\hline 4 & $\mathrm{C}$ & A & A & A & 2 & 9.5 \\
\hline total & & & & & 21 & 100.0 \\
\hline
\end{tabular}

a) MtDNA types were classified by combining the enzyme morphs for each individual.

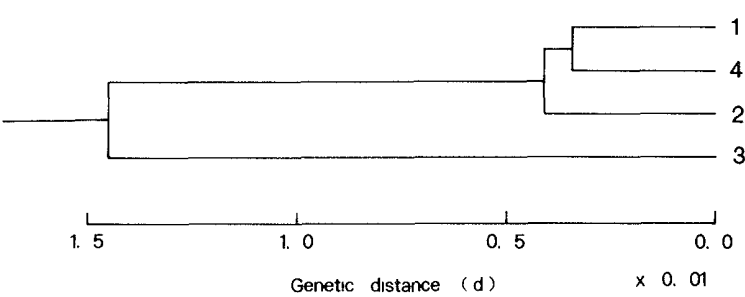

Fig. 5. A phylogenetic tree based on the genetic distance for Jindo dogs. The genetic distance for Jindo dogs was calculated by the method of Nei \& $\mathrm{Li}$ as described in MATERIALS AND METHODS. The numbers at the right end show mtDNA types in Jindo dogs. 
MtDNA types, nucleotide diversity, and phylogenetic trees of Jindo dog mtDNA: Based on the combination of restriction endonuclease morphs observed in 21 Jindo dogs, we summarized the mtDNA types (Table 3 ). The mtDNA types in Jindo dogs were classified into 4 distinct mtDNA restriction types. The frequency of the dominant type, type $1 \mathrm{mtDNA}$ in Jindo dogs, was $71.4 \%$. The average amount of nucleotide change in Jindo dog mtDNA can be estimated by the method of cleavage site compositions [6]. Genetic distances for the mtDNA types were calculated and the phylogenetic tree in Jindo dogs was constructed by the UPG (Unweighted Pair-Group Clustering) method (Fig. 5). In the Jindo dog tree only one cluster was observed. Applying the equations of $\mathrm{Nei}$ and $\mathrm{Li}[6]$ to the data in Table 3, the mean value for the Jindo dog was estimated to be 0.0086 .

DISCUSSION

In this study, we have investigated the polymorphism of Jindo dog mtDNA with Japanese mongrel dog mtDNA as a probe. The mtDNA polymorphisms in the Jindo dog were observed with Apa I, EcoR V, Hinc II, and Sty I. Three morphs using Apa I and two morphs using EcoR V, Hinc II and Sty I were found in the present study. These morphs could be derived one from the other by single changes thought to be point mutation. The 21 Jindo dogs were classified into 4 types using four restriction endonucleases. The value of nucleotide diversity in Jindo dogs was calculated to be 0.0086 , and the UPGMA tree had only one cluster. This suggests that the pedigree of Jindo dogs is really preserved and they are still a considerably pure species.

The polymorphism of 20 Japanese mongrel dogs was examined in the same way by Tsuchida and Ikemoto [9]. In the Japanese mongrel dog, mtDNA polymorphisms were observed with EcoR I in addition to $A p a \mathrm{I}, E c o \mathrm{R}$ V, Hinc II and Sty I; the digestion patterns with EcoR I showed three morphs (morph A, B, and C). In Eco R I cleavage patterns, the original morph was thought to be morph A. It seems from their data that morph $\mathrm{B}$ in mongrel dogs resulted in a new site within the $7.3 \mathrm{~kb}$ band of morph $\mathrm{A}$, and morph $\mathrm{C}$ is generated by the loss of the $8.4 \mathrm{~kb}$ band of morph $\mathrm{A}$. The polymorphisms cleaved by the other 4 restriction endonucleases were detected as the result of Jindo dog mtDNA polymorphism. The 20 mongrel dogs were classified into 7 types with ten restriction endonucleases and the value of nucleotide diversity was calculated to be 0.0094 . A phylogenetic tree constructed by genetic distances among the 7 types showed at least two clusters of mtDNA types.

We also compared the number and frequency of mtDNA polymorphisms in Jindo dog and Japanese mongrel dog. Apa I polymorphisms in Jindo dog were classified in morph $\mathrm{A}, \mathrm{B}$, and $\mathrm{C}$ and the frequencies were $71.5 \%, 19.0 \%$, and $9.5 \%$, respectively. On the other hand, the frequency of Japanese mongrel dogs with Apa I polymorphisms was different from that of Jindo dogs; that of mongrel dogs with morph A was $20.0 \%$, and morph B was the most frequent $(45.0 \%)$. This diversity may result in the gain of a single Apa I site by point mutation. The digestion pattern with EcoR I in Jindo dog was also only morph $\mathrm{A}$, but in mongrel $\operatorname{dog}$ were morph $\mathrm{A}, \mathrm{B}$, and $\mathrm{C}$. This fact indicates that morph $\mathrm{A}$ is the original pattern and morph $\mathrm{B}$ and $\mathrm{C}$ are generated by gaining a new EcoR I site because of the point mutation in the evolutionary process. In the tree of the mongrel dog at least two clusters of mtDNA types were observed, but in that of the Jindo dog only one cluster was observed. This suggests that the species of the Jindo dog is at present maintained on Jin Island by the Korean government. As the genetic distances between both breeds were almost equal, it is felt that their ancestors were very similar to each other.

Hashimoto et al. [3] reported on the two sialic acid species (N-acetylneuraminic acid and N-glycolylneuraminic acid), controlled by an autosomal dominant allele, constituting the terminal sugar residues of hematosides from various breeds of dog erythrocytes. In their study they demonstrated that the percentage of $\mathrm{N}$ glycolylneuraminic acid was higher in natural breeds in northern China, Korea and the southern part of Japan than in other oriental breeds, while the Hokkaido dog did not have $\mathrm{N}$-glycolylneuraminic acid at all. The gene frequency of $\mathrm{N}$-acetylneuraminic acid and $\mathrm{N}$ glycolylneuraminic acid in the Jindo dog was 0.499 and 0.501 , respectively. This frequency agrees with that of breeds in northern China and the southern part of Japan on the whole. These results suppose that the native breeds in the southern part of Japan came from northern China via the Korean peninsula. Tanabe [8] has also analyzed 14 genetic loci controlling polymorphic variations in blood protein components and discussed a marked difference between the genetic compositions in Japanese native dog breeds and European dog breeds. They concluded that Korean native dogs were related to the native breeds in the southern part of Japan, and about 2,300 years ago new human populations, followed by different breeds of dogs, migrated to the southern part of Japan from the Korean peninsula, resulting in cross-breeding of Japanese native dogs with the invaders.

The results of mtDNA polymorphism analyses in Jindo dogs and Japanese mongrel dogs support the notion that Japanese mongrel dogs came from the Korean peninsula. Consequently, these data seem to sustain the hypothesis of Hashimoto et al. [3] and Tanabe [8]. However, the origin of Japanese dogs is still controversial. Therefore, the analysis of mtDNA polymorphism in the dog is useful in investigating the relationship among the breeds of dogs. Further studies on other breeds of dogs and additional restriction endonucleases will be essential to clarify the origin, differentiation, and classification of dogs.

ACKnowledgement. We thank Dr. Shuichi Tsuchida, Department of Legal Medicine, Jichi Medical School, for his useful suggestions. 
REFERENCES

1. Brown, W. M., George, M. Jr., and Wilson, A. C. 1979. Rapid evolution of animal mitochondrial DNA. Proc. Natl. Acad. Sci. U.S.A. 76: 1967-1971.

2. Brown, W. M., Prager, E. M., Wang, A., and Wilson, A. C. 1982. Mitochondrial DNA sequences of primates: Tempo and mode of evolution. J. Mol. Evol. 18: 225-239.

3. Hashimoto, Y., Yamakawa, T., and Tanabe, Y. 1984. Further studies on the red cell glycolipids of various breeds of dogs. A possible assumption about the origin of Japanese dogs. J. Biochem. (Tokyo) 96: 1777-1782.

4. Hutchison III, C. A., Newbold, J. E., Potter, S. S., and Edgell, M. H. 1974. Maternal inheritance of mammalian mitochondrial DNA. Nature (Lond.) 251: 536-538.

5. Lansman, R. A., Shade, R. O., and Avise, J. C. 1981. The use of restriction endonucleases to measure mitochondrial DNA sequence relatedness in natural populations III. Techniques and potential applications. J. Mol. Evol. 17: 214-226.

6. Nei, M. and Li, W-H. 1979. Mathematical model for studying genetic variation in terms of restriction endonucleases. Proc. Natl. Acad. Sci. U.S.A. 76: 5269-5273.

7. Potter, S. S., Newbold, J. E., Hutchison III, C. A., and Edgell, M. H. 1975. Specific cleavage analysis of mamma- lian mitochondrial DNA. Proc. Natl. Acad. Sci. U.S.A. 72: 4496-4500.

8. Tanabe, Y. 1984. The origin of the Japanese dog and the completion of its differentiation. Report for the grant from the Ministry of Education Science and Culture of Japan No. 57360018: 71-92 (in Japanese).

9. Tsuchida, S. and Ikemoto, S. 1992. Mitochondrial DNA polymorphism in dogs. J. Vet. Med. Sci. 54: 417-424.

10. Watanabe, T., Hayashi, Y., Ogasawara, N., and Tomita, T. 1985a. Polymorphism of mitochondrial DNA in pigs based on restriction endonuclease cleavage patterns. Biochem. Genet. 23: 105-113.

11. Watanabe, T., Hayashi, Y., Semba, R., and Ogasawara, N. 1985b. Bovine mitochondrial DNA polymorphism in restriction endonuclease cleavage patterns and the location of the polymorphic site. Biochem. Genet. 23: 947-957.

12. Watanabe, T., Masangkay, J. S., Wakana, S., Saito, N., and Tomita, T. 1989. Mitochondrial DNA polymorphism in native Philippine cattle based on restriction endonuclease cleavage patterns. Biochem. Genet. 27: 431-438.

13. Yonekawa, H., Moriwaki, K., Gotoh, O., Miyashita, N., Migita, S., Bonhomme, F., Hjorth, J. P., and Petras, M. L. 1982. Origins of laboratory mice deduced from restriction patterns of mitochondrial DNA. Differentiation 22: 222-226. 